Romagnoli, F.C.; Scabin, A.; Pegas, F.V. Boto-vermelho (Inia geofrensis): espécie bandeira para promoção do Ecoturismo na Amazônia Central, Brasil. Anais do VIII Congresso Nacional de Ecoturismo e do IV Encontro Interdisciplinar de Ecoturismo em Unidades de Conservação. Revista Brasileira de Ecoturismo, São Paulo, v.4, n.4, 2011, p. 518.

\title{
BOTO-VERMELHO (Inia geofrensis): ESPÉCIE BANDEIRA PARA PROMOÇÃO DO ECOTURISMO NA AMAZÔNIA CENTRAL, BRASIL
}

\author{
Fernanda Carneiro Romagnoli*, Andressa Scabin, Fernanda de Vasconcellos Pegas ${ }^{\star * *}$ \\ *Ministério da Educação, **Instituto Nacional de Pesquisas da Amazônia, \\ ${ }^{* * *}$ Griffith University - International Centre for Ecotourism Research \\ E-mails: fcarneiroromagnoli@gmail.com, dedascabin@gmail.com, f.pegas@griffith.edu.au
}

O ecoturismo é uma estratégia que integra conservação da natureza e desenvolvimento econômico, gerando benefícios para o ambiente e para comunidades locais. As principais formas de promover a conservação via ecoturismo são por meio da educação ambiental de turistas e da sensibilização de moradores locais quanto a importância dos recursos naturais com os quais convivem. Uma maneira de promover o ecoturismo é utilizando espécies bandeira como atrativos. Espécies bandeira são aquelas carismáticas, que criam uma relação afetiva com o publico. Uma espécie bandeira que pode contribuir com a conservação da Amazônia via ecoturismo é o botovermelho (Inia geofrensis). Bastante carismático, já tem sido muito procurado por turistas. Sua principal ameaça atual é a utilização como isca na pesca do peixe conhecido como piracatinga, alem de ser morto por pescadores que o consideram competidor na pesca e que o mata em retaliação, por danificarem as redes. Os botos-vermelhos são tradicionalmente conhecidos pelas lendas a seu respeito, que os colocam como seres encantados, capazes de trazer azar e fazer mal a quem os perturbe, além de serem grandes sedutores de mulheres. Assim, o presente estudo analisa aspectos sócio-culturais na relação entre os moradores do município de Novo Airão, Amazonas, Brasil e os boto-vermelhos que possam influenciar a utilização dessa espécie como espécie bandeira para a promoção de ecoturismo no Parque Nacional (PARNA) de Anavilhanas, no Baixo Rio Negro. As análises foram feitas a partir das informações de uma dissertação de mestrado, que realizou 111 entrevistas semi-estruturadas com moradores do município de Novo Airão em novembro 2008. Os resultados indicam que os moradores locais consideram o turismo de interação com botos-vermelhos uma atividade muito importante para Novo Airão, pois atrai um grande número de turistas. Também acreditam que esta atividade faz com que muito dinheiro entre na economia local, apesar da maioria deles não estar envolvida. As lendas a respeito dos botos-vemelhos vêm perdendo forca, principalmente devido à miscigenação na região e ao aumento do contato com os botos, muito proporcionado pelo turismo que os envolve. Apesar disso, ainda ha resistência de aproximação dos moradores mais velhos e de mulheres. Assim, por um lado, o turismo aproxima as pessoas dos botos e quebra mitos. Por outro, esta aproximação também pode ter uma lado negativo, uma vez que as pessoas deixam de temer estes animais e podem afrontá-los. Contudo, a aproximação das comunidades locais aos botos-vermelhos gerada pelas atividades de turismo pode gerar muito mais benefícios a conservação desta espécie, a seu habitat e a Amazônia do que malefícios. O sucesso dos projetos de ecoturismo está fortemente ligado a relação entre as comunidades receptoras com espécies bandeiras, assim como ao suporte e a participação local no processo de implementação dos projetos turísticos. Assim, o envolvimento dos moradores e imprescindível para que o ecoturismo fomente uma relação positiva e gere beneficios para a conservação ambiental, assim como para a própria manutenção da atividade turística local, via geração de renda para as comunidades envolvidas.

Palavras-chave: Espécie Bandeira; Conservação; Botos; Valores culturais. 